\section{THE POSITION OF NATURAL SCIENCE IN EDUCATION.}

THE report (Cd. 90II, price $9 d$. net) of Sir J. J. Thomson's Committee appointed in 1916 to inquire into the position of natural science in the educational system of Great Britain has now been published, and we propose to deal with its main points in a later issue. It is a valuable survey of the position of science in schools and in relation to professional and university education. The case for increased attention to science in order to expand the mental outlook as well as equip the nation with the elements of industrial progress is so strong that it has already convinced all who have considered it. What remains to be done now is to act upon the principles set forth in the report, and if the stress of war has not shown the necessity for such action by our political rulers national disaster will do so when too late. It is pointed out that there has been no general and sufficient recognition of science as an essential part of the curriculum for all boys in the public schools, and that in grant-aided secondary schools the customary course of science work is too narrow, to the neglect of great scientific principles with their human interests and everyday applications. More trained scientific workers are needed, and to secure them there must be a generous extension of the system of scholarships and greatly increased contributions from the State for university and technical education. "If," says the report, "the universities are to discharge their responsibilities towards the science students who are coming, and to maintain their position as homes of scientific learning and research, they must receive a measure of financial support much more considerable than they have received hitherto." The report concludes with a summarv of principal conclusions under eighty-three heads, a selection from which is reprinted below.

General.-Natural science should be included in the general course of education of all up to the age of about sixteen. Real progress in education depends on a revolution in the public attitude towards the salaries of teachers and the importance of their training. A large increase in the number of scholarships at all stages of education is necessary.

Secondary Schools.-Steps should be taken to secure for all pupils in State-aided secondary schools a school life beginning not later than twelve and extending at least up to sixteen. Science should be included in the general course of education for all pupils in public and other secondary schools un to the age of about sixteen, and this general course should be followed by more specialised study, whether in science or in other subjects. In all secondary schools for boys the time given to science should be not fewer than four periods in the first year of the course from twelve to sixteen, and not fewer than six periods in the three succeeding years. Increased attention should be given to the teaching of science in girls' schools. In girls' schools with a twenty-four-hour school week not fewer than three hours per week should be devoted to science in the period twelve to sixteen. A larger number of State-aided schools should be encouraged to provide advanced instruction in science, and those which undertake advanced work should be staffed on a more generous scale. The elements of natural science should be a necessary subject in the entrance examination of public schools, and due weight should be given to this subject in the entrance scholarship examinations to public schools.

Science Course Trelve to Sixteen.-The science work for pupils under sixteen should be planned as a NO. 2529 , VOL. IOI] self-contained course, and should include, besides physics and chemistry, some study of plant and animal life. More attention should be directed to those aspects of the sciences which bear directly on the objects and experience of everyday life. There should be as close correlation as possible between the teaching of mathematics and science at all stages in school work. The present chaos of English weights and measures causes waste of time and confusion of thought, and there are strong educational reasons for the adoption of the metric system. All through the science course stress should be laid on the accurate use of the English language.

Science Course Sixteen to Eighteen.-The amount of time devoted from sixteen to eighteen to the subject or subjects in which a pupil is specialising should be not less than one-half or more than two-thirds of the school week. Pupils specialising in science should continue some literary study, and those specialising in literary subjects should give some time to science work of an appropriate kind. Pupils who do advanced work in science should be enabled to acquire a reading knowledge of French and German. Eighteen should be the normal age of entry from secondary schools to the universities, and the age limit for entrance scholarships at Oxford and Cambridge should be reduced to eighteen.

Examinations.-In the First School Examination all candidates should be required to satisfy the examiners both in mathematics and in natural science. In this examination there should be co-operation between the teachers and examiners, and weight should be attached to the pupil's school record.

Teachers in Secondary Schools.-It is essential that the salaries and prospects of teachers in secondary schools should be substantially improved and a national pension scheme provided. A full year's training shared between school and university is necessary for all teachers in secondary schools.

Laboratories. - The teachers in State-aided schools should be given freedom and responsibility in the selection and purchase of laboratory appliances up to a fixed annual amount.

Elementary Schools.-Increased attention should be given to the provision of suitable instruction in science in the upper standards of elementary schools. A larger number of students in training colleges should be encouraged to take advanced courses in science. There should be in every elementary school a room in addition to the ordinary classroom accommodation available for work in science and other practical subjects.

Technical Education.-Greater efforts should be made to develop and increase the provision of instruction in pure and in applied science in technical schools and institutions of all grades. Many more scholarships are needed to enable technical students to pass on to the universities, and also to enable boys from junior technical schools (or their equivalent) and from evening schools to enter senior technical schools. The position of junior technical schools in the educational system should be reconsidered. It is essential that the salaries and prospects of teachers in technical schools should be substantially improved, and a national pension scheme provided for whole-time teachers. In the proposed continuation classes provision should be made for instruction in science both in its general aspects and in its bearing on industry.

Medicine.-The First School Examination should be recognised by the General Medical Council as qualifying for entrance into the medical profession. Students should be allowed to take the First Professional Examination in $(a)$ chemistry and physics, and (b) biology 
before entering the university or medical school. More scholarships should be provided for candidates of both sexes tenable throughout the medical course.

Engineering.-A thorough and practical training in mathematics and science is essential to the school education of engineers; it cannot be replaced and need not be supplemented at school by prartice in an engineering workshop.

Agriculture.-Specific instruction in agriculture or agricultural science should not be given in elementary or secondary schools, though in favourable circumstances a rural bias may be given to the work of a secondary school. All county education authorities xcting either singly or in co-operation should provide well-equipped farm institutes for their areas.

Army.-Science should be an obligatory subject in the examination for entrance into the Royal Military College, Sandhurst, and be included in the course of instruction in the college. Steps should be taken to improve the efficiency of the instruction in science at the Royal Military Academy, Woolwich. More encouragement should be given to officers at later stages of their career to improve their scientific qualifications.

Home and India Civil Service.-An inquiry should be made as to the best methods of securing the services of scientific men for the purposes of the State in permanent posts and otherwise. Many permanent posts can best be filled by men selected, not by the ordinary competitive examination, but at a riper age on the ground of high scientific qualifications and professional experience. All candidates for the competitive examination for these services should supply evidence of a continuous course of training in science extending over several years. To ensure sufficient catholicity in questions propounded in the viva-voce examination, these examiners should include some representative of science.

University Education.-The universities should adopt the First School Examination as the normal examination for admission, and should abolish special matriculation examinations for candidates from schools. Greek should not be retained as a necessary subject in Responsions at Oxford or the Previous Examination at Cambridge. The universities should make special arrangements to test the fitness for entrance of candidates who are above twenty-three years of age.

Degree Courses in Science at the Universities.-The Universities of Oxford and Cambridge should arrange to provide more suitable courses in science for candidates who do not aim at an honours degree. Candidates for the university intermediate examinations should be allowed to take the examinations from school. The universities should recognise the Second School Examination as alternative to the whole or part of their intermediate examinations. It is desirable that a year spent mainly on research should form part of the work of university students preparing for careers concerned with science and its applications: but this should follow the course for a first degree in science. Scholarships are needed to enable a young graduate to spend a year or more in research, at his own or at another university.

State Aid to the Universities.-Large expenditure of public money is necessary to equip the universities for their wurk in pure and in applied science. Grants from public funds to the universities should be increaseu to allow the universities to make a substantial reduction in their fees.

University Teachers.-The duties of junior lemonstrators should be limited so that they can spend a considerable amount of time on research. There NO. 2529 , VOL. IOI] should be posts of substantial value in university de partments for senior men whose best work lies in teaching. The heads of technological departments should be allowed to undertake private professional practice.

Scottish Universities.-Steps should be taken to remove the limitations which confine a large proportion of the old-established bursaries to the faculty of arts.

Scholarships at Schools and Universities.-Scholarships should be considered as distinctions awarded in recognition of intellectual merit and promise. All scholarships should be of nominal value, to be supplemented according to need. Where necessary the whole cost of a scholar's education and maintenance should be defrayed. Scholarships at the universities should be tenable for at least three years with a possibility of extension. Scholarships awarded by local education authorities should not be restricted to particular universities. Scholarships at the universities should be awarded on a wider range of subjects than at present. The age limit for scholarships at Oxford and Cambridge should be eighteen rather than nineteen. Scholarships should not be awarded on work done in large pass examinations for schools. Scholarships to the universities for candidates from technical and evening schools should be awarded without an age limit, and for the present on a limited range of subjects. The number of scholarships at the women's colleges should be increased. Loan funds should be tstablished to enable senior students to obtain professional training.

Supply of Trained Scientific Workers.-Concerted efforts should be made by employers, teachers, local education authorities, and the State to. increase the flow of capable students to the universities and higher technical institutions with the view of securing the larger supply of trained scientific workers required for industrial and other purposes.

\section{APPLICATIONS OF ELECTRICITY TO $M E D I C I N E$.}

THE Institution of Electrical Engineers devoted an evening meeting last: week to a visit to the Cancer Hospital, Fulham Road, S.W, The occasion was a joint meeting of the members of the institution and the members of the Electrotherapeutic Section of the Royal Society of Medicine. Two papers were read by medical men, and there was a large and representative exhibition of radiographic and electrical apparatus used in the diagnosis and treatment of disease.

The modern and thoroughly well equipped research institute of the hospital, under the direction of Dr. Alexander Paine, was thrown open to the visitors, who had an opportunity of seeing the inner working arrangements of several laboratories equipped for research work in physics, pathology, bacteriology, chemistry, and other subjects associated with the investigation of disease by modern methods.

The governing body of the Cancer Hospital has always exercised a wise judgment in the adoption of new methods for the investigation of the causation of disease, its diagnosis and treatment. This hospital was one of the first in this country to recognise the therapeutic use of $\mathrm{X}$-rays and other electrical methods in the treatment of malignant disease. So far back as 1903 it inaugurated a very complete $\mathrm{X}$-ray department, which was carried on for several years under the directorship of Dr. J. D. Pollock.

In Igr I the research institute was ready for work, and a year or two later the scheme for modernising the special branches of the hospital work was completed by the equipment of the new electrical and radiotherapeutic department, which is housed in a 